ISSN 0258-7122 (Print), 2408-8293 (Online)

Bangladesh J. Agril. Res. 42(1): 185-190, March 2017

Short Communication

\title{
EFFECT OF LIGHT QUALITY AND PLANT GROWTH REGULATOR ON ORGANOGENESIS OF ORKID Cymbidium dayanum
}

\begin{abstract}
S. J. NAHAR ${ }^{1}$, S. M. HAQUE ${ }^{2}$ AND K. SHIMASAKI ${ }^{3}$
Keywords: Chitosan, hyaluronic acid, polysaccharide, protocorm-like body, tissue culture

Orchids include some of the world's most important floricultural (cut-flower) and ornamental (pot and garden) plants (Teixeira da Silva, 2013). Cymbidium dayanum is important evergreen, epiphytic orchid which is valued for their attractive flowers. This species that is quite widespread from Northern India right through to Japan and is one of the most sought after ornamentals in local cut flower market. In recent years, the population of $C$. dayanum has declined rapidly due to unregulated heavy collection, excessive habitat destruction and deforestation. C. dayanum had been declared as vulnerable and threatened orchid in Red Data Book (Nayar and Sastry, 1990). There is an increasing risk of this important orchid becoming extinct from its natural habitat if uncontrolled exploitation continues unabated (Nongdam and Chongtham, 2012). Effective conservation strategies should be devised to prevent further loss of the already depleted of this orchid population. The in vitro approach through the application of plant tissue culture technology provides an excellent opportunity for effective conservation by mass propagating orchids in short time span. Though there are several reports on tissue culture of different orchids, the micropropagation of $C$. dayanum has been very less documented in the literature.
\end{abstract}

Light is one of the basic factors needed by plant for its development. Tissue culture and growth rooms have long been using artificial light sources, including fluorescent lamps, high pressure sodium lamps, metal halide lamps, and incandescent lamps, etc. Among these, fluorescent lamps have been the most popular in tissue culture rooms (Economou and Read, 1987). In recent years, light emitting diodes (LEDs) have been proposed as a primary light source for space-based plant research chambers or bioregenerative life-support systems, and a potential alternative light source for in vitro plant growth and development (Bula et al., 1991; Yeh and Chung, 2009). Ki-Ho Son and Myung-Min (2013) reported that, LEDs have some advantages over traditional lighting sources in plant cultivation due to high light-conversion efficiency with low radiant heat output, have variety of narrow wavebands would be possible to optimize light quality to improve both crop yield and quality.

Plant growth regulator is indispensable material in culture media, and is important to the plant tissue induction, organ differentiation and growth. The use of elicitors in crop protection and pest management is still in the very early stages

${ }^{1-3}$ Faculty of Agriculture, Kochi University, Nankoku, Kochi 783-8502, Japan. 
of use as a new control method (Thakur and Singh, 2013). Plants treated with elicitors develop a general resistance. Chitosan and hyaluronic acid is well known elicitors; chitosan, obtained primarily from the exoskeleton of crustaceans, but also found in cuticles of insects as in the cell walls of fungi and some algae, is one of the most common polymers that could be found. Chitosan has had a strongly positive effect on many growth responses in a number of plants, including orchids (Kaewjampa et al., 2010; Nahar et al., 2011; Teixeira da Silva, 2013) the mechanism of action remains unknown. Hyaluronic acid (HA), composed of glucuronic acid and $\mathrm{N}$-acetyl glucosamine joined alternately by $\beta-1-3$ and $\beta-1-4$ glycosidic bonds, has biological functions in lower and higher organisms, including in cell adhesion, migration, proliferation and differentiation, regulation of protein secration and gene expression (reviewed by Fraser et al., 1997). HA suppresses disease in cucumber, tomato and pepper (Park et al., 2008) and has shown to have antioxidant activity. HA have of recent been suggested as important components of Cymbidium in vitro culture media (Nahar et al., 2011, 2012; Nahar and Shimasaki, 2014; Kaewjampa et al., 2012). Therefore, the objective of this study was to investigate the effect of light quality and plant growth regulator on organogenesis of C. dayanum in vitro.

Protocorm-like bodies (PLBs) of Cymbidium dayanum were collected from local orchid growers. PLBs of $C$. dayanum were proliferated in the modified MS medium (Shimasaki and Uemoto, 1990) by transferring to a new medium every two months. After excision of PLB (appox. $5 \mathrm{~mm}$ in diameter) into pieces, they were used for explants. The experiment was conducted at the Lab. of Vegetables and Floriculture Science, Faculty of Agriculture, Kochi University, Japan from May, 2013 to June, 2013 (five weeks). MS medium with $412.5 \mathrm{mg} \mathrm{l}^{-1}$ ammonium nitrate, $950 \mathrm{mg} \mathrm{l}^{-1}$ potassium nitrate, $20 \mathrm{~g} \mathrm{l}^{-1}$ sucrose, and $2 \mathrm{~g} \mathrm{l}^{-1}$ Phytagel (Sigma) was adjusted to $\mathrm{pH} 5.5-5.8$ before autoclaving. Plant growth regulators (PGRs) like chitosan (Chitosan H- Kimica Co., Japan) and hyaluronic acid (HA9- Shiseido, Japan) were added to culture media at different concentrations (control, 0.1 and $1 \mathrm{mg} \mathrm{l}^{-1}$, ) before sterilization to ascertain the growth response of the culture. Jars of $250 \mathrm{ml}$ (UM culture bottle, As one, Japan) with plastic caps were used, each bottle receiving $30 \mathrm{ml}$ of medium. The experiment was performed by taking 15 replicates for each treatment. Five explants were placed in each culture vessel and three culture vessels were used for each treatment.

The cultures of in vitro plantlets were illuminated using different light conditions of photon flux density (PFD) of $50 \mu$ mole $\mathrm{m}^{-2} \mathrm{~s}^{-1}$. Three sources of light were used: red LED (Jefcom, P18W-E1701-R, peak wavelength: $640 \mathrm{~nm}$ ), blue LED (Jefcom, P18W-E1701-B, peak wavelength: $450 \mathrm{~nm}$ ) and green LED (Jefcom, P18W-E1701-G, peak wavelength: $510 \mathrm{~nm}$ ). The plantlets were exposed to a 16 $\mathrm{h}$ photoperiod for 5 weeks. Experimental data were collected after 5 weeks of 
culture by counting the average number of PLBs, shoots and roots; percentage of PLB, shoot and root and the fresh weight of PLBs were measured. The average and percentage was derived by using the formula given below: Average number of PLB: number of PLB/one PLB explants

Percentage of formation $=\frac{\text { Number of culture explants with new PLB/ shoot }}{\text { Total number of culture explant }} \times 100$

The data were statistically analyzed by calculating standard errors of the means (means $\pm \mathrm{SE}$ ) and significant differences assessed by Tukey HSD test $(\mathrm{P} \leq 0.05)$.

The growth and development of protocorm-like bodies (PLBs) of $C$. dayanum were affected under different sources of lights. Addition of hyaluronic acid and chitosan with modified MS media, PGRs enhanced the better formation of PLBs, shoot and root within short duration of culture periods. The significance different observed under blue and green LED by hyaluronic acid (HA9) and chitosan (Chitosan H) treatments. The highest formation of PLB (93\%) and shoot (53\%) were observed that the PLBs cultured at $1 \mathrm{mg} / \mathrm{l} \mathrm{HA} 9$ with modified MS medium under blue LED (Table 1) while $1 \mathrm{mg} / \mathrm{l}$ chitosan promoted $80 \%$ PLB formation under red LED and green LED (Table $2 \& 3$ ). The average number of PLB (5.6 PLBs/explant) and shoot (1.5 shoots/explant) were significantly increased under blue LED with $1 \mathrm{mg} / \mathrm{l} \mathrm{HA} 9$ treatment (Table 1). Meanwhile the lowest number of PLB (0.9 PLBs/explants) and shoot (0.3 shoots/explants) were grown under green LED at control (Table 3). The root formation and the fresh weight (FW) of PLBs were recorded. The maximum fresh weight of PLBs $(101.1 \mathrm{mg})$ and the highest root formation (40\%) were observed under red LED with $1 \mathrm{mg} / \mathrm{l}$ chitosan treatment (Table 2).

Table 1. Effect of different concentrations (control, 0.1 and $1 \mathrm{mg} / \mathrm{l}$ ) of chitosan (Chi H) and hyaluronic acid (HA) with modified MS medium on protocorm-like bodies (PLBs) of $C$. dayanum under blue LED

\begin{tabular}{l|cc|c|c|c|c|c}
\hline \multirow{2}{*}{$\begin{array}{c}\text { Treatment } \\
(\mathrm{mg} / \mathrm{l})\end{array}$} & \multicolumn{3}{|c|}{ PLB } & \multicolumn{2}{c|}{ Shoot } & \multicolumn{2}{c}{ Root } \\
\cline { 2 - 8 } & No./explant & $\begin{array}{c}\text { Rate } \\
(\%)\end{array}$ & $\begin{array}{c}\text { FW } \\
(\mathrm{mg})\end{array}$ & No./explant & $\begin{array}{c}\text { Rate } \\
(\%)\end{array}$ & No./explant & $\begin{array}{c}\text { Rate } \\
(\%)\end{array}$ \\
\hline Control & $2.7 \pm 1.0 \mathrm{~b}$ & 60 & $51.4 \pm 7.4 \mathrm{ab}$ & $0.2 \pm 0.2 \mathrm{~b}$ & 20 & $0.2 \pm 0.2$ & 20 \\
Chi H 0.1 & $1.4 \pm 1.0 \mathrm{ab}$ & 33 & $37.8 \pm 11.3 \mathrm{~b}$ & $0.5 \pm 0.5 \mathrm{~b}$ & 27 & $0.2 \pm 0.2$ & 20 \\
Chi H 1 & $2.1 \pm 1.0 \mathrm{a}$ & 53 & $46.6 \pm 6.4 \mathrm{ab}$ & $0.3 \pm 0.3 \mathrm{~b}$ & 20 & $0.2 \pm 0.2$ & 20 \\
HA 0.1 & $2.0 \pm 0.6 \mathrm{ab}$ & 67 & $52.1 \pm 11.7 \mathrm{ab}$ & $0.5 \pm 0.5 \mathrm{~b}$ & 27 & $0.3 \pm 0.3$ & 27 \\
HA 1 & $5.6 \pm 1.3 \mathrm{ab}$ & 93 & $87.5 \pm 19.5 \mathrm{a}$ & $1.5 \pm 0.7 \mathrm{a}$ & 53 & $0.4 \pm 0.3$ & 33 \\
\hline
\end{tabular}

The data were statistically analyzed by calculating standard errors of the means (means \pm $\mathrm{SE})$ and different letters show significant differences by Tukey HSD test $(\mathrm{P} \leq 0.05)$. Fresh weight $=\mathrm{FW}$. 
Table 2: Effect of different concentrations (control, 0.1 and $1 \mathrm{mg} / \mathrm{l}$ ) of chitosan (Chi H) and hyaluronic acid (HA) with modified MS medium on protocorm-like bodies (PLBs) of $C$. dayanum under red LED

\begin{tabular}{l|c|c|c|c|c|c|c}
\hline \multirow{2}{*}{$\begin{array}{c}\text { Treatment } \\
(\mathrm{mg} / \mathrm{l})\end{array}$} & No./explant & $\begin{array}{c}\text { Rate } \\
(\%)\end{array}$ & FW(mg) & No./explant & $\begin{array}{c}\text { Rate } \\
(\%)\end{array}$ & No./explant & $\begin{array}{c}\text { Rate } \\
(\%)\end{array}$ \\
\cline { 2 - 8 } & $3.3 \pm 1.1$ & 67 & $79.0 \pm 12.9 \mathrm{a}$ & $0.4 \pm 0.2$ & 40 & $0.2 \pm 0.2$ & 20 \\
\hline Control & $3.3 \pm 1$ & \multicolumn{2}{|c|}{ PLB } & \multicolumn{2}{c|}{ Root } \\
Chi H 0.1 & $3.9 \pm 2.2$ & 47 & $67.7 \pm 14.2 \mathrm{a}$ & $0.5 \pm 0.5$ & 27 & $0.3 \pm 0.3$ & 20 \\
Chi H 1 & $5.3 \pm 1.7$ & 80 & $101.1 \pm 13.9 \mathrm{a}$ & $0.6 \pm 0.3$ & 47 & $0.6 \pm 0.3$ & 40 \\
HA 0.1 & $3.0 \pm 1.1$ & 67 & $62.4 \pm 12.5 \mathrm{a}$ & $0.5 \pm 0.4$ & 33 & $0.3 \pm 0.3$ & 20 \\
HA 1 & $3.6 \pm 1.2$ & 73 & $66.6 \pm 10.5 \mathrm{a}$ & $0.5 \pm 0.4$ & 33 & $0.3 \pm 0.4$ & 20 \\
\hline
\end{tabular}

The data were statistically analyzed by calculating standard errors of the means (means \pm $\mathrm{SE})$ and different letters show significant differences by Tukey HSD test $(\mathrm{P} \leq 0.05)$. Fresh weight $=$ FW.

Table 3. Effect of different concentrations (control, 0.1 and $1 \mathrm{mg} / \mathrm{l})$ of chitosan (Chi H) and hyaluronic acid (HA) with modified MS medium on protocorm-like bodies (PLBs) of C. dayanum under green LED

\begin{tabular}{l|c|c|c|c|c|c|c}
\hline \multirow{2}{*}{$\begin{array}{c}\text { Treatment } \\
(\mathrm{mg} / \mathrm{l})\end{array}$} & \multicolumn{3}{|c|}{ PLB } & \multicolumn{2}{c|}{ Shoot } & \multicolumn{2}{c}{ Root } \\
\cline { 2 - 8 } & No./explant & $\begin{array}{c}\text { Rate } \\
(\%)\end{array}$ & FW(mg) & No./explant & $\begin{array}{c}\text { Rate } \\
(\%)\end{array}$ & No./explant & $\begin{array}{c}\text { Rate } \\
(\%)\end{array}$ \\
\hline Control & $0.9 \pm 0.6 \mathrm{ab}$ & 33 & $38.9 \pm 6.5$ & $0.3 \pm 0.2$ & 33 & $0.3 \pm 0.2$ & 27 \\
Chi H 0.1 & $1.9 \pm 1.4 \mathrm{ab}$ & 33 & $43.1 \pm 10.7$ & $0.5 \pm 0.5$ & 27 & $0.2 \pm 0.4$ & 13 \\
Chi H 1 & $5.3 \pm 1.7 \mathrm{a}$ & 80 & $65.7 \pm 8.9$ & $0.7 \pm 0.4$ & 40 & 0 & 0 \\
HA 0.1 & $3.7 \pm 1.5 \mathrm{~b}$ & 53 & $53.5 \pm 12.0$ & $0.4 \pm 0.6$ & 20 & 0 & 0 \\
HA 1 & $2.9 \pm 1.4 \mathrm{~b}$ & 53 & $73.6 \pm 15.0$ & $0.7 \pm 0.5$ & 40 & $0.4 \pm 0.4$ & 27 \\
\hline
\end{tabular}

The data were statistically analyzed by calculating standard errors of the means (means \pm $\mathrm{SE})$ and different letters show significant differences by Tukey HSD test $(\mathrm{P} \leq 0.05)$. Fresh weight $=\mathrm{FW}$.

Light directly influences plant growth and flowering by inducing photosynthesis and feeding plants energy. Plants are dependent on light to generate food, induce the growing cycle and allow for healthy development. LEDs began to be investigated for germinating seeds and rooting cuttings in the Netherlands (Nijssen et al., 1990) and for tissue culture systems in Japan (Miyashita et al., 1995). Initial studies included only red LEDs because they were the most efficient and emit light that coincides with the maximum absorption of chlorophyll $(660 \mathrm{~nm})$. However, it quickly became apparent that some blue light was necessary for normal growth and development of soybean, wheat, lettuce ( Dougher and Bugbee, 2001; Yorio et al., 2001) spinach, and radish (Yorio et al., 2001). This study showed the results that blue LEDs had good effects on new PLBs and shoot formation; the root formation and fresh weight became higher under red LED. Sultana et al. (2014) reported that blue and red LED plays an important role in stimulating PLBs and shoot formation of Dendrobium 
kingianum; our results agree with these previous findings and additionally show that blue LEDs are more efficient to induce new PLB and shoot of Cymbidium dayanum (Fig.1). To increase the efficiency of in vitro techniques, plant growth regulators are frequently used for orchids (Shimasaki and Uemoto, 1990; Teixeira da Silva, 2014). Cymbidium is rapidly turning into a model orchid, if not a model plant, at least for in vitro studies due to the fine scale nature of experiments conducted on this genus (Teixeira da Silva, 2014). LEDs lights are suitable and new technology for the culture of plants in a tightly controlled environment such as space based plant culture systems. Additionally, chitosan and HA added with culture medium helps to induce new PLBs and shoot in Cymbidium dayanum within short duration of culture in vitro. The present study revealed that these newly developed light sources will be protect Cymbidium dayanum from extinction.
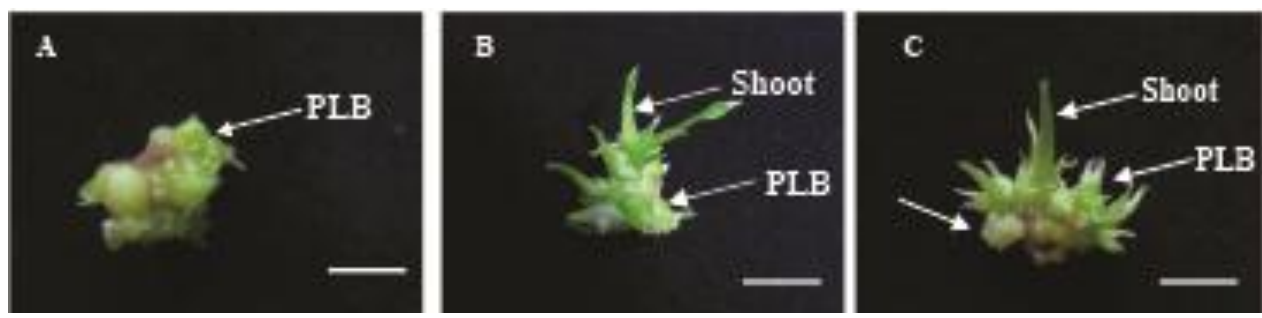

Fig 1. Effect of hyaluronic acid and chitosan on organogenesis of Cymbidium dayanum under three LED lights. A: Control (Green LED); B: 1 mg/l HA9 (Blue LED); C: $1 \mathrm{mg} / \mathrm{l}$ chitosan (Red LED); Bar $=10 \mathrm{~mm}$.

\section{References}

Bula, R. J., R. C. Morrow, T. W. Tibbitts, D. J. Barta, R. W. Ignatius and T. S. Martin. 1991. Light-emitting diodes as a radiation source for plants. Hort Science. 26: 203-205.

Dougher, T. A. O. and B. Bugbee. 2001. Differences in the response of wheat, soybean and lettuce to reduced blue radiation. Photochemistry and Photobiology. 73: 199-207.

Economou, A.S. and P.E. Read. 1987. Light treatments to improve efficiency of in vitro propagation systems. Hort Sci. 22: 751-754.

Fraser, J. R. E, T. C. Lauran, and U. B. G. Laurent. 1997. Hyaluronic: its nature, distribution, functions and turnover. J. Internal med. 242: 27-33.

Kaewjampa, N., K. Shimasaki and S. J. Nahar. 2012. Hyaluronic acid can be a new plant growth regulator for hybrid Cymbidium micropropagation. Plant Tissue Culture \& Biotech. 22: 59-64.

Kaewjampa, N., K. Shimasaki, H. C. Li and S. J. Nahar. 2010. Effects of biopolysaccharide on organogenesis in orchid in vitro. Proceedings of the 1 st Kamphaengsaen, International Natural Products Symposium, Thailand. 37-42.

Ki-Ho, S. and O. Myung-Min. 2013. Leaf shape, growth, and antioxidant phenolic compounds of two lettuce cultivars grown under various combinations of blue and red light-emitting diodes. Hort Science. 48: 988-995. 
Miyashita, Y., Y. Kitaya, C. Kubota, T. Kozai, and T. Kimura. 1995. Effects of red and far-red light on the growth and morphology of potato plantlets in vitro: Using light emitting diodes as a light source for micropropagation. Acta Horticulturae. 393: 189-194.

Nahar, S. J., K. Shimasaki, C. L. Huang and N. Kaewjampa. 2011. Effect of plant growth regulators on organogenesis in protocorm-like body (PLBs) of Cymbidium dayanum in vitro. ARPN J. Agril. \& Biolog. Sci. 6: 28-33.

Nahar, S. J., K. Shimasaki and S. M. Haque. 2012. Effect of different light and two polysaccharides on the proliferation of protocrom-like bodies of Cymbidium cultured in vitro. Acta Horticulturae, 956: 307-311.

Nahar, S.J. and K. Shimasaki. 2014. Effect of Hyaluronic acid on organogenesis in protocorm-like body (PLB) of some Cymbidium species in vitro. Acta Horticulturae. 1025: $237-242$.

Nayar, M.P. and A. R. K. Sastry. 1990. Red Data Book of Indian Plants. Vol. 3, Botanical Survey of India, Calcutta.

Nijssen, C., O. Kuhn, and W. Verbeek. 1990. Method and device for lighting seeds or plants. U.S. Patent. 4: 914, 858.

Nongdam, P. and N. Chongtham. 2012. In vitro seed germination and mass propagation of Cymbidium dayanum Reichb: An important ornamental orchid of North-East Indian. Trends in Horticultural Research. 2: 28-37.

Park, K., D. Pau, E. Kim and W. K. P. P. Joseph. 2008. Hyaluronic acid of Streptococcus sp. as a potent elicitor for induction of systemic resistance against plant diseases. World Journal of Microbial Biotech. 24: 1153-1158.

Shimasaki, K. and S. Uemoto. 1990. Micropropagation of a terrestrial Cymbidium species using rhizomes developed from seeds and pseudobulbs, Plant Cell Tissue and Organ Culture. 22: 237-244.

Sultana, U.H., K. Shimasaki, Ahasan, M.M and Alam, M.M. 2014. Effects of different light quality on growth and development of protocorm-like bodies (PLBs) in Dendrobium kingianum cultured in vitro. Bangladesh Research Publications Journal, 10 (2): 223-227.

Teixeira da Silva. 2013. Orchids: advances in tissue culture genetics, phytochemistry and transgenic biotechnology. Floriculture and Ornamental Biotechnology. 7: 1-52.

Teixeira da Silva. 2014. Response of hybrid Cymbidium (Orchidaceae) protocorm-like bodies to 26 plant growth regulators. Botanica Lithuanica. 20: 3-13.

Thakur, M., and B. S. Singh. 2013. Role of elicitors in inducing resistance in plants against pathogen infection: A review. ISRN Biochemistry. 2013: 1-10.

Yeh, H. and J.P. Chung. 2009. High-brightness LEDs-energy efficient lighting sources and their potential in indoor plant cultivation. Renew Sust Energy Rev. 13:2175-2180

Yorio, N.C., G. Goins, H. Kagie, R. Wheeler, and J. C. Sager. 2001. Improving spinach, radish,and lettuce growth under red LEDs with blue light supplementation. Hort Sci. 36: $380-383$. 